Volume 2, Issue 2, April-June 2017, Pages: 171, DOI: http://dx.doi.org/10.19082/ah171

\title{
ONE-YEAR REGISTRY OF ACUTE STEMI PATIENTS IN THREE REFERRAL CARDIOVASCULAR CENTERS IN ISFAHAN 2015 TO 2016
}

Azam Soleimani, Masume Sadeghi, Amir Hossein Mirmohammad Sadeghi, Maede Azarm, Neda Dorostkar

Cardiac Rehabilitation Research Center, Cardiovascular Research Institute, Isfahan University of Medical Sciences, Isfahan, Iran

Correspondence:

A. Soleimani MD, Tel: 09133126859, E-mail: asoleimanii@gmail.com

\section{TYPE OF ARTICLE: CONFERENCE ABSTRACT}

\begin{abstract}
Introduction: We aimed to organize a full data registry and follow-up of patients with ST elevation myocardial infarction (STEMI) admitted to three main cardiac hospitals in Isfahan. These data will be a fundamental basis for evaluation of treatment strategies and to produce national guidelines for STEMI treatment in the future.

Methods: This is an international prospective, multi-center, observational study in collaboration with the European Society of Cardiology and as a part of the PROVE program in Isfahan that has performed from October 2015 to 2016. For all acute STEMI patients admitted to three main cardiac hospitals (Chamran, Feiz and Nour) demographic, clinical, laboratory, echocardiographic and angiographic data was collected. Exact time intervals, management patterns, use of reperfusion therapies (including thrombolytic and primary percutaneous coronary intervention) and in-hospital outcomes were recorded, and if the patients were transferred to Chamran hospital (for PCI), follow-up was continued there. A quality control committee evaluated the data in a randomized model, periodically. The one-year followup visit of the patients is under performance currently. After completion of the questionnaires, the data were entered online on the EURObservational Research Program site.

Results \& Conclusion: During one year, data of more than 1,200 patients who presented with acute STEMI within 24 hours of symptom onset had been collected. The data will be analyzed internationally after entering it into an automated quality control program performed by the European team.

Conclusion: This well qualified registry will be the basis and guide to develop the registry of all types
\end{abstract} of heart disease in Iran.

KEYWORDS: Acute myocardial infarction, Percutaneous Transluminal Coronary Angioplasty, Fibrinolytic therapy, Registry, Outcomes Assessment

\footnotetext{
Abstracts of First National Congress of Medical Informatics, Mashhad, Iran, February 2017

(C) 2017 The Authors. This is an open access article under the terms of the Creative Commons Attribution-NonCommercialNoDerivs License, which permits use and distribution in any medium, provided the original work is properly cited, the use is non-commercial and no modifications or adaptations are made.
} 